\title{
A STUDY OF COMPLEXES BETWEEN CYTOSINE \\ AND AMINO ACID CARBOXYLIC GROUP BY NMR SPECTROSCOPY
}

I. V. Kondratyuk, I. N. Kolomiets, S. A. Samoilenko, N. V. Zheltousky

Institute of Molecular Biology and Genelics,

$\Lambda$ cademy of Sciences of the Ukrainian S'SR, Kicv

Sum a : y

It has been shown by UV spectroscopy that of all the nucleotide bases only cytosine interacts with undissociated amino acid carboxylic group in DMSO solution. H-bonded complexes of cytosine with some amino acid $\mathrm{N}$-acyl derivatives ( $\mathrm{N}$-formyl aspartic acid, $\mathrm{N}$ acetyl aspartic acid, $\alpha$-methyl ester of $\mathrm{N}$-acetyl aspartic acid, $\mathrm{N}$-acetyl gitutaic acid, $\mathrm{N}$ formyl giycinc) were studied by the PMR spectroscopy. It has been determined by ${ }^{13} \mathrm{C} \mathrm{NMR}$ spectroscopy that while complexing cytosine is protonated at N3 atom by carboxylic group proton. It was showil that in triple complex $\mathrm{N}$-formyl aspartic acid: cytosine: 9-methyl guanine amino acid carboxylic group, binding to cytosine, loosens $\mathrm{H}$-bonds inside the base pair.

\section{СПИСОК ЛИТЕРАТУРЫ}

1. Bзанлодейстөие нуклсотидных основапй с карбоксильной группой амилокислот в ДМСО: модель точечных белково-нуклеиновых колтактов / Н. В. Желтовский, С. А. Самойлелко, И. Н. Коломиец, И. В. Кондратюк // Докл. АН УССР. Сер. Б.1988. ㅈo 8.-. C. 68 - 71 .

2. Lancelot $G$., Helene $C$. Selective recognition of nucleic acids by proteins: The specificity of guanine interaction with carboxylate-ion//PNAS. - 1977.-74, N 11.— P. $4872-4875$.

3. Брусков В. Н., Бущуев В. Н. Исследование методом протопюого магиитпого резонанса комплексообразовапия между нуклеозидами и соединениями, моделирующими аминокислотные остатки белков, в диметилсульфоксиде // Биофизика.— 1977.22, № 1.-- C. $26-31$

4. Carbon-13 magnetic resonance. 17. Pyrimidine and purine nuc'eosides/A. J. Jones, D. M. Grant, M. W. Winkley, R. K. Robins; J. Mmer. Cilem. Soc.-- 1970.-92, X 13.P. $4079-4087$

5. Breitmaier E., Voelter W'. Carbon-13 NMR spectroscopy.-Weinhein : VCH, 1987.

6. Job $M$. $P$. Etude spectrographique de la formation des complexes en solution ef de Icur stabi'ite // Compt. Rend. $\rightarrow$ I925.-180, N 12.- P. 928-930

7. Comparative structural ana'ysis of cytidine, ethenocytidine and their protonated salts III. $\mathrm{H},{ }^{13} \mathrm{C}$ and ${ }^{15} \mathrm{~N}$. NMR studies at normal isotope abundance / I. Kozersti, H. Sierzpulowska-Cracz, W. Krzyzosiak et al.//Nucl. Acids Res.-1984.-12, N 4.P. $2205-2223$.

8. Benoit $R$. L., Frechete $M$. 'H and ${ }^{13} \mathrm{C}$ nuclear magnetic resonance an uitraviolet studies of the protonation of cytosine, uracil, thymine, and related compotnds $/ /$ Can. J. Chem.- 1986.-64, N $12 .-$ P. 2348-235.2.

9. Колебательний спектр и структура комплекса цитозина с твердой фазе / Н. В. Желтовский, С. А. Самойленко, М. И. Губайдуллин, И. В. Кондратіо // Докл. АН УССР. Сер. Б.- 1988- № 5.- С. $75-78$.

10. Studies of virus structure by aser-raman spectroscopy. Tump yellow mosaic virus and capsids/K. A. Hartman, P. E. McDona'd-Ordzic, J. M. Kaper et al.//Bioche11ristry.-1978-17, N 1:1.-P. 2118-2123.

Ин-т молекуляр. биологии и генетики М I УССР, Киез

Получено 23.06 .89

YIIK $577.3: 547.963 .3$

С. В. Корнилова, А. Г. Шкорбатов, Ю. П. Благой

ВЛИЯНИЕ ИОНОВ ІҢЕЛОЧНОЗЕМЕЛЬНЫХ

И ПЕРЕХОДНЫХ МЕТАЛЛОВ НА ГИДРОДИНАМИЧЕСКИЕ

И МАКРОМОЛЕКУЛЯРНЫЕ ПАРАМЕТРЫ ДНК

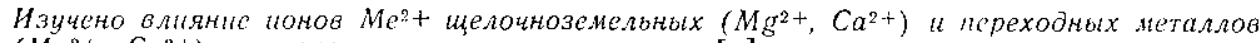
$\left(\mathrm{Mn}^{2+}, \mathrm{Cu} \mathrm{L}^{+}\right)$на характеристическую вязкость [1] и величину парам'тра исключен.

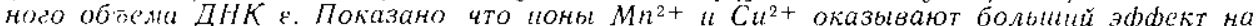

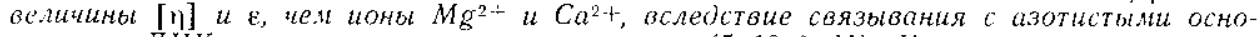
ванияни ДНК уже при малих концентрациях $\left(5 \cdot 10^{-6} \mathrm{M}\right)$. Установлено умиверсаль-

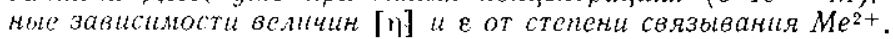


Введение. Активная биологическая роль ионов двухвалентных металлов в процессах жизнедеятельности, в канцерогенезе и мутагенезе определяет интерес $\mathrm{K}$ исследованию взаимодействия ионов с макромолекулами ДНК. Однако механизмь влияния катионов на структуру и физические свойста ДНК выяснены недостаточно полно. В настояцей работе рассмотрены малоизученные вопросы, связанные с различием действия ионов щелочноземельных и переходных металлов на конформацию ДНК, молекулярные параметры и величину исключенного объема. Изучено связывание ионов $\mathrm{Mg}^{2+}, \mathrm{Ca}^{2+}, \mathrm{Mn}^{2+}$ и $\mathrm{Cu}^{2+} \mathrm{c}$ ДНК в широком диапазоне иониых сил $\left(2 \cdot\left(10^{-4}-10^{-1}\right) \mathrm{M}\right)$ и выполнен количественныӥ анализ влияния степени связывания ща конформационные лараметры макромолекул.

Материалы и методы. Исследования проводили на препаратах ДНК, выделенных из тнмуса теленка и содержащих примеси двухвалентных ионов $\left(\mathrm{Me}^{2+}\right)$ в концентрации не более $5 \cdot 10^{-4} \mathrm{M} \mathrm{Me}{ }^{2+}$ на моль фосфора. Содержание белка и PHK не превышало 0,5 и 0,1\% соответственно. Препараты ДНК обладали следующими харакгернстнками, которые сохранялись на протяжении всей серии экспериментов: $\mathrm{A}_{260 / 230}=2,39 \pm 0,01, \mathrm{~A}_{260 / 280}=1,85 \pm 0,02$, величина гипохромного эффекта $39 \%$, коэффициент мо.Іярпой экстинкции 6600. Молекулярная масса (м. м.) ДНК составляла

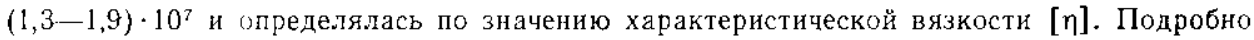

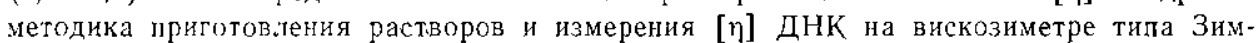
ма-Крозерса иписана в наших предыдущих работах $[1,2]$. Исследования были выполнень при температуре $24,0 \pm 0,05^{\circ} \mathrm{C}$ в растворах с рН $6,4 \pm 0,05$. В условиях низкой ионнй силь $\left(2 \cdot 10^{-1} \mathrm{M} \mathrm{Na} \mathrm{Na}^{+}\right)$измерения [ๆ] ДНК проводили при $16 \pm 0,05^{\circ} \mathrm{C}$ и градиентах скорости $g<0,03 \mathrm{c}^{-1}$. Концентрации двухвалентных ионов металлов, вводимых в виде хлоридов, определяли по массе и контролировали методом трилонометрического титрования. Коццентрации свободых ионов металлов и параметр связывания $r$ чис.тенно оценивали по уравнениям Скетчарда дія системы ионов, учитывающих конкуренцию при связывании $[3,4]$.

Результаты и обсуждение. Экспериментальные зависнмости характеристической вязкости ДІК от концентрации ионов $\mathrm{Mg}^{2+}$ и $\mathrm{Ca}^{2+}$ при различном содержании $\mathrm{Na}^{-\dagger}$ в растворе (рис. 1) свидетельствуют о том,

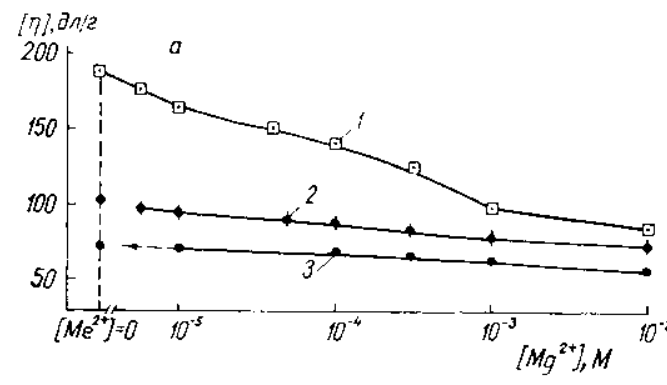

Pис. 1. Зависимости характернститеской вязкости ДНК от концентрации нонов $\mathrm{Mg}^{2++}\left(\right.$ a) и $\mathrm{Ca}^{2+}($ (b) при раз.лнчном содержании $\mathrm{Na}+: 1-10^{-3} ; 2-10^{-2} ; 3--10^{-3}$ $4-2 \cdot 10^{-4} \mathrm{H}$

Fig. 1. The DNA intrinsic viscosity depen dences on $M g^{2+}(a)$ and $\mathrm{Ca}^{2+}(6)$ ion concentrations with different $\mathrm{NaCl}$ contents: $1-10^{-3} \mathrm{M} \therefore \mathrm{a}+2-10^{-2} \mathrm{M} \mathrm{Na}^{+} ; 3-$ $10^{-3} \mathrm{MNa}, 4-2 \cdot 10^{-:} M \mathrm{Na}$

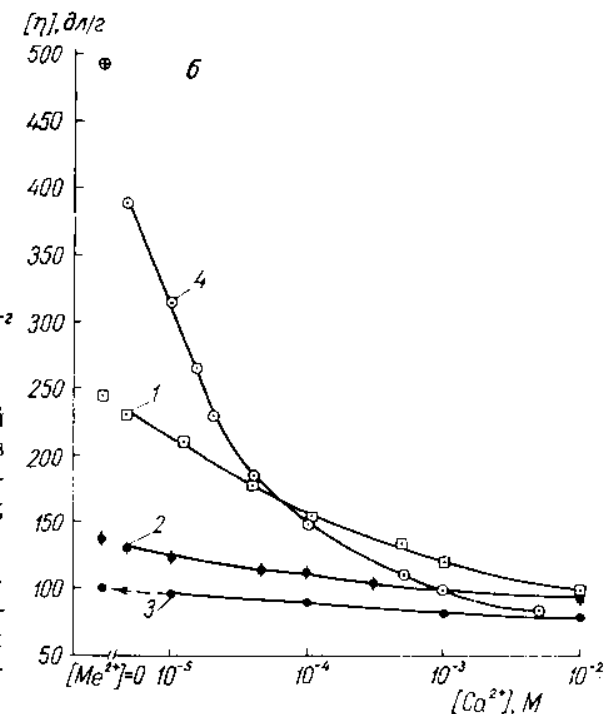

что уже малые концентрации ионов щелочноземельных металлов

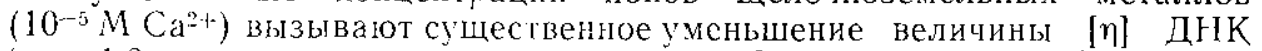
(в $\sim 1,2$ раза по сравнению со зпачением $[\eta]$ в растворе $10^{-3} \mathrm{Ml} \mathrm{Na}^{+}$). Сравнение относительных изменений [1] ДНК, соответствуюших одинаковым концептрациям двухвалентных ионов и ионов $\mathrm{Na}^{+}$, показывает, что при $10^{-3} \mathrm{M} \mathrm{Na}^{+}$и концентрациях $\mathrm{Ca}^{2+}>10^{-4} \mathrm{M}$ ионы $\mathrm{Ca}^{2}$ оказывают боньнес влияние на $[\eta]$ ДI]K. ГІри высоком содержанин $\mathrm{Na}^{+}$ 
$(\geqslant 0,01)$ значения [ $\eta]$ ДНК, соответствующие одинаковым концентрациям ионов $\mathrm{Ca}^{2+}$ и $\mathrm{Mg}^{2+}$, становятся близкими, что согласуется с ре-

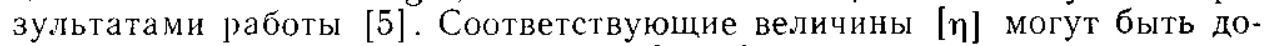
стигнуты в растворах $\mathrm{NaCl} п$ пи $\left[\mathrm{Na}^{+}\right] \simeq 1 \mathrm{M}$.

Сравнивая действие ионов переходных и щелочноземельных металлов на характеристическую вязкость, можно видеть (рис. 2), что при одинаковых концентрациях $\mathrm{Na}^{+}$ионы $\mathrm{Mn}^{2+}$ и $\mathrm{Cu}^{2+}$ вызывают более значительное уменьшение [ $\eta]$ ДНК, чем ионы $\mathrm{Mg}^{2+}$ и $\mathrm{Ca}^{2+}$, и что особенно сильным оказывается влияние ионов $\mathrm{Cu}^{2+}$. В настоящей работе обнаружены различия в действии $\mathrm{Mg}^{2+}$ и $\mathrm{Mn}^{2+}$ на характеристическую вяз-
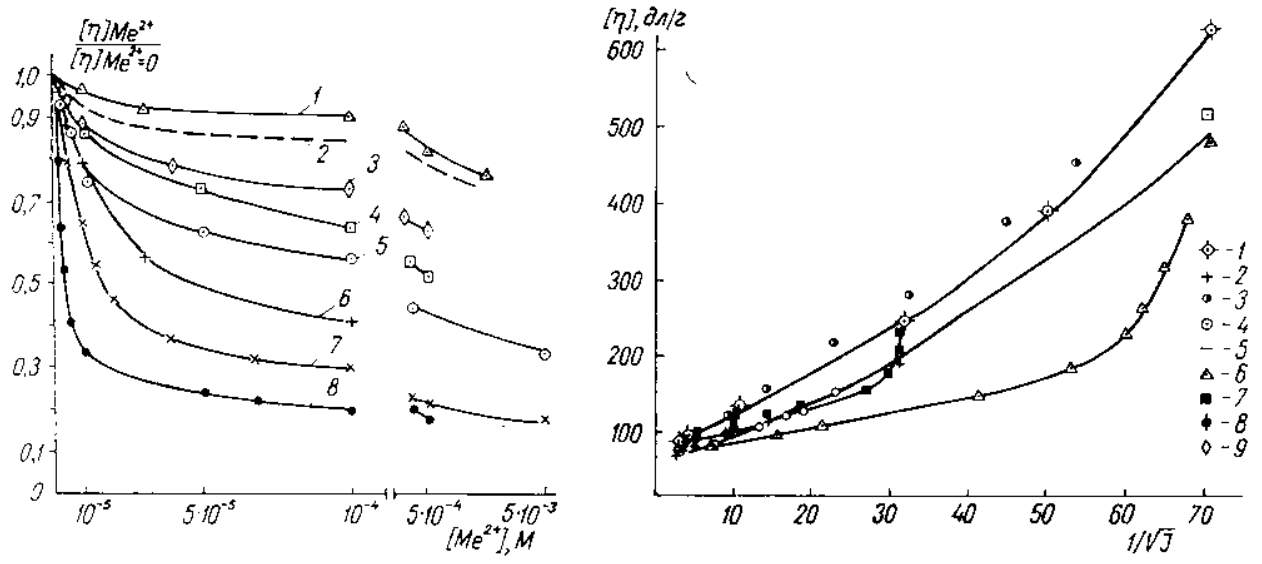

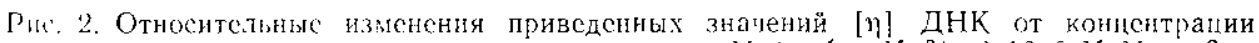

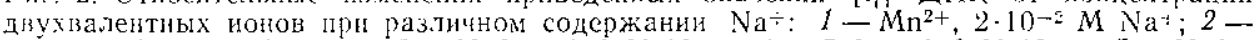
$\mathrm{Mr}^{2+}, \mathrm{Ca}^{2+}, 10^{-2} \mathrm{M} \mathrm{Na}^{+}: 3-\mathrm{Mg}^{2+}, 10^{-3} \mathrm{M} \mathrm{Na}+4-\mathrm{Ca}^{2+}, 10^{-3} \mathrm{M} \mathrm{Na}+5-\mathrm{Mn}^{2+}$, $10^{-3} \mathrm{M} \mathrm{Na}{ }^{+} ; 6-\mathrm{Cu}^{2+}, 10^{-3} \mathrm{M} \times \mathrm{Na}^{+} ; 7-\mathrm{Ca}^{2+}, 2 \cdot 10^{-4} \mathrm{M} \mathrm{Na}^{+} ; 8-\mathrm{Mn}^{2+}, 2 \cdot 10^{-4} \mathrm{M} \mathrm{Na}^{+}$ Fig. 2. The relative changes of [1] values of DNA due to the bivalent ion concentrations with different $\mathrm{NaCl}$ contents: $1-\mathrm{Mn}^{2+}, 2 \cdot 10^{-2} \mathrm{M} \mathrm{Na+;} 2-\mathrm{Mg}^{2+}, \mathrm{Ca}^{2+}, 10^{-2} \mathrm{Na}^{+*}$; $3-\mathrm{Mg}^{2+}, 10^{-3} \mathrm{M} \mathrm{Na}^{--} ; 4-\mathrm{Ca}^{2+}, \quad 10^{-3} \mathrm{M} \mathrm{Na}^{+} ; 5-\mathrm{Mn}^{2+}, 10^{-3} \mathrm{M} \mathrm{Na}^{+} ; 6-\mathrm{Cu}^{2+-}$, $10^{-3} \mathrm{M} \mathrm{Na}{ }^{+} ; 7-\mathrm{Ca}^{2--}, 2 \cdot 10^{-4} \mathrm{M} \mathrm{Na}{ }^{+} ; 8-\mathrm{Mn}^{2+}, 2 \cdot 10^{-4} \mathrm{M} \mathrm{Na}^{+}$

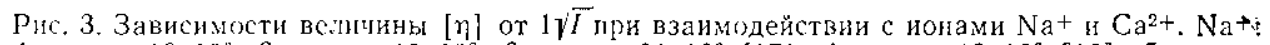
1 - м. м. $19 \cdot 10^{6}: 2$ - м. м. $13 \cdot 10^{6} ; 3$-м. м. $21 \cdot 10^{6}[17]: 4-$ м. м. $13 \cdot 10^{6}[18] ; 5-$ м. м.

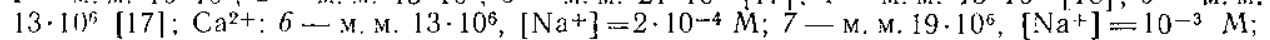
8 - v. M. $19 \cdot 10^{6},[\mathrm{Na}+\}=10^{-2} \mathrm{M} ; 9$ - M. . . $19 \cdot 10^{6},\left[\mathrm{Na}^{+}\right]=10^{-1} \mathrm{M}$

Fig. 3. The [I] value dependece on $1 / \sqrt{I}$ during the binding to $\mathrm{Na}+$ and $\mathrm{Ca}^{2+}$ ions. $\mathrm{Na}^{+}$: $1-$ m. w. $19 \cdot 10^{6} ; 2-$ m. w. $13 \cdot 10^{6} ; 3-$ w. m. $21 \cdot 10^{6}[17] ; 4-$ m. w. $13 \cdot 10^{6}[18] ; 5-$ - m. w. $13 \cdot 10^{6}[17] ; \mathrm{Ca}^{2} \div ; 6-$ m. w. $13 \cdot 10^{6},[\mathrm{Na}]^{+}=2 \cdot 10^{-4} \mathrm{M} ; 7-\mathrm{m}$. w. $19 \cdot 10^{6}$; $\left[\mathrm{Na}^{-}\right]=10^{-3} \mathrm{M} ; 8-\mathrm{m}$. w. $19 \cdot 10^{6},\left[\mathrm{Na}^{+}\right]=10^{-2} \mathrm{M} ; 9-\mathrm{m} . \mathrm{w} \cdot 19 \cdot 10^{6},\left[\mathrm{Na}^{+}\right]=10^{-1} \mathrm{M}$

кость ДНК при концентрации $\mathrm{Me}^{2+}$ в растворе $10^{\cdots 6}-10^{-5} \mathrm{M}$, что соответствует степеням связывания $r_{1} \simeq 0,2$ при $\left[\mathrm{Na}^{+}\right]=10^{-3} \mathrm{M}$. Метод диализа гцротив низкой концентрации двухвалентлых ионов, использованный в работе [5], не позволил обнаружить различий между действием $\mathrm{Mn}^{2+}$ и $\mathrm{Mg}^{2+}$, так как приводит к значительно бо́льним значениям параметра связывания $r_{t} \sim 0,4$, при которых влняние $\mathrm{Me}^{2+}$ на $[\eta]$ ЦНК осуществляется, в основном, по механизму дебай-хюккелевского экранирования.

Сильная нелинейность зависимости $[\eta]$ ДНК от $1 / \sqrt{I}$ (I- ионная сила раствора) в присутствии $\mathrm{Me}^{2+}$ обусловлена связыванием двухвалентных ионов с ДІІК (рис. 3). Двухвалентные ионы $\left(\mathrm{Me}^{2+}\right)$ присутствуют в растворе в соотношении $\left[\mathrm{Me}^{2+}\right] \ll\left[\mathrm{Na}^{+}\right]\left(10^{-6}-10^{-5} \mathrm{M} \mathrm{Me}^{2+}\right.$ и $\left.2 \cdot\left(10^{-4}-10^{-3}\right) \mathrm{M} \mathrm{Na}{ }^{+}\right)$. В таком случае частичное связывание двухвалентных ионов с ДІІК практически не меняет ионной силы раствора, и уменьшение [n] нельзя объяснить усилением дебай-хюккелевского экранирования отрицательных зарялов ДНК при повышении общеї ионной силы раствора. Вследствие высоких значений констант связывания $\mathrm{Me}^{2+}$ с ДІІК $[3,6 \mid$ уже при малых их концентрациях число двух- 
валентных ионов, связанных с макромолекулой, значительно. Это приводит к сильному уменьшению объема, занимаемого макромолекулой ДІК, что определяет уменьшение ее [ๆ] в результате частичной компенсации отрицательного заряда при равновесном связывании ионов. При больших концентрациях $\mathrm{Me}^{2+}$ наряду со связыванием следует учитывать и их экранирующее действие.

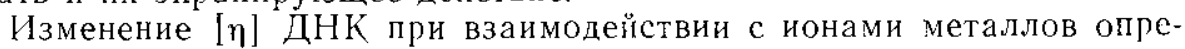
деляется изменением дальнодействия в макромолекуле, описываемого.
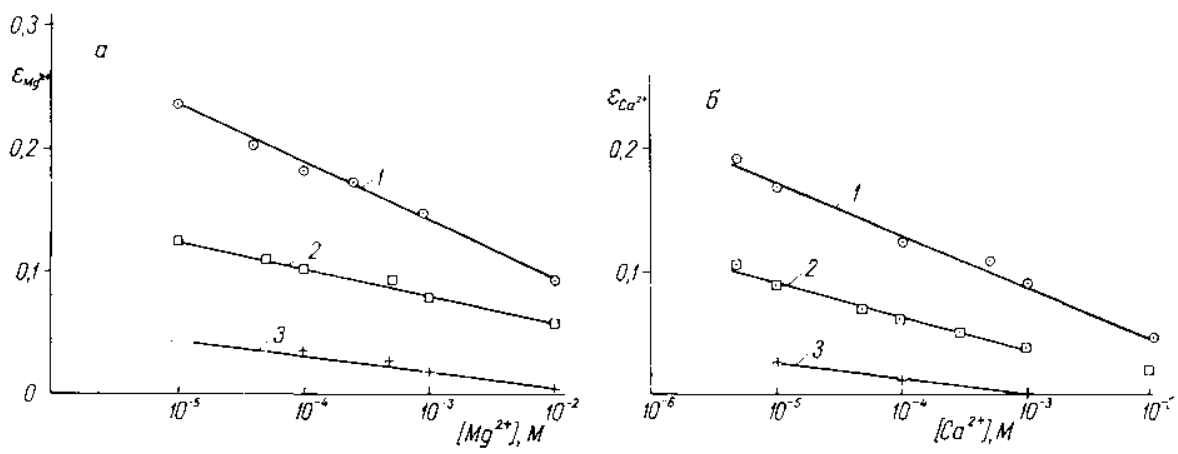

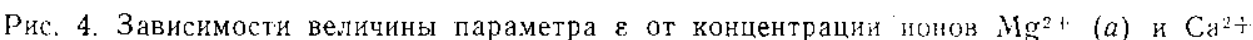
(б) при разном содержании ㅊà $1: I-10^{-3} ; 2-10^{-2} ; 3-10^{-1} \mathrm{M}$

Fig. 4. The parameter $\varepsilon$ dependences on the $\mathrm{Mg}^{2}+(a)$ and $\mathrm{Ca}^{2+}(\sigma)$ concentrations with different $\mathrm{NaCl}$ contents. $1-10^{-3} ; 2-10^{-2} ; 3--10^{-1} \mathrm{M} \mathrm{Na}^{-1}$

параметром исключенного объема $\varepsilon$, и близкодействия, которое ответственно за величину персистентной длины $a$. Представляется интересным оценить вклад дальнодействия в изменение размеров ДНК при взаимодействии с двухвалентными ионами, так как предполагается, что.

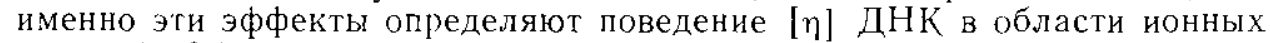
сил $\sim 10^{-3} \mathrm{M}$ и выше.

Чтобы рассчитать параметр исключенного объема ДНК при различных концентрациях ионов металлов, мы использовали подход, описанный нами ранее [4].

При вычислениях учитывали слабую зависимость персистентнов длины ДНК от концентрации ионов $\mathrm{Na}^{+}$в области [NaCl] $>10^{-3} \mathrm{M}$ $[7,8]$, а для двухвалентных ионов - в области $\left[\mathrm{Mg}^{2+}\right] \geqslant 6 \cdot 10^{-5} \mathrm{M}$, что соответствует $I>2 \cdot 10^{-4} M[8]$. В связи с этим допускали, что увеличение $\left[\mathrm{Me}^{2+}\right]$ в растворе $10^{-3} \mathrm{M} \mathrm{Na}{ }^{+}$не вызывает изменений величины $a$, и полагали $a=60$ лм $[7,8]$. При бо́лыших ионных силах, в соответствии с даниыми работ [7-9], считали $a=50$ нм. Значение [ $\eta]$ в точке $\Theta$

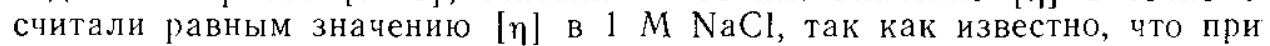
увеличении концентрации противононов свыше $1 M$ величина характеристической вязкости остается практически постоянной вследствие полного подавления электростатических объемных эффектов $[5,7,10]$. Параметр исключенного объема ДІК в $\Theta$ точке приняли равным 0 , так как имевшиеся в литературе данные о высоких значениях $\varepsilon$ при больших ионных силах связаны, как показывает анализ, с сильным завышением эффектов исключенного объема [9].

Сравнивая действие ионов переходных и щелопноземельных металлов на эффекты дальнодействия в макромолекуле ДНК, можно видеть (рис. 4, 5), что связывание ионов $\mathrm{Mn}^{2+}$ и $\mathrm{Cu}^{2+}$ при концентрациях $\mathrm{Mn}^{2 \cdot+} \sim 10^{-3} \mathrm{M}$ и $\mathrm{Cu}^{2+} \sim 10^{-4} \mathrm{M}$ приводит к значительному уменьшению параметра $\varepsilon$, в то время как для ионов $\mathrm{Mg}^{2+}$ и $\mathrm{Ca}^{2+}$ эти значения $\varepsilon$ достигаются при концентрациях $\sim 10^{-2} M$ и выше.

Исследование, выполненное нами ранее [11] методами кругового дихронзма (КД) и УФ-дифференциальной спектроскопии, показывает,

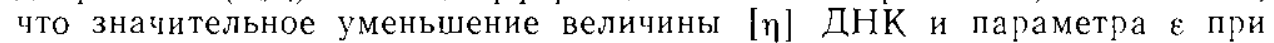
добавлении малых количеств $\mathrm{Me}^{2+}\left(\sim 10^{-5} \mathrm{M}\right)$ coпровождается актив- 
ным связыванием двухвалентных ионов с фосфатами и азотистыми основаниями макромолекул. Так, при концентрациях ионов $\mathrm{Mn}^{2+}$ и $\mathrm{Cu}^{2+}$ $5 \cdot 10^{-6} \mathrm{M}$ в растворе $10^{-3} \mathrm{M} \mathrm{Na}+$ можно наблюдать дифференциальный УФ-спектр (ДУФС) комплексов ДНК, свидетельствующий о связывании этих ионов с основаниями, а также изменение оптической активности положительной полосы спектра КД ДНК (рис. 6). В отличие от нонов переходных металлов ионы $\mathrm{Mg}^{2+}$ не взаимодействуют с азотистыми основаниями ДНК $[6,12]$. Только при $5 \cdot 10^{-3} \mathrm{M} \mathrm{Ca}^{2+}$ в растворе, содержащем $10^{-3} \mathrm{M} \mathrm{Na}^{+}$, можно наблюдать ДУФС ДНК в комплексе с ионами $\mathrm{Ca}^{2+}$, а также значительное уменьшение оптической активности положительної полосы спектра КД, свидетельствующие о связывании $\mathrm{Ca}^{2+}$ с основаниями ДНК.
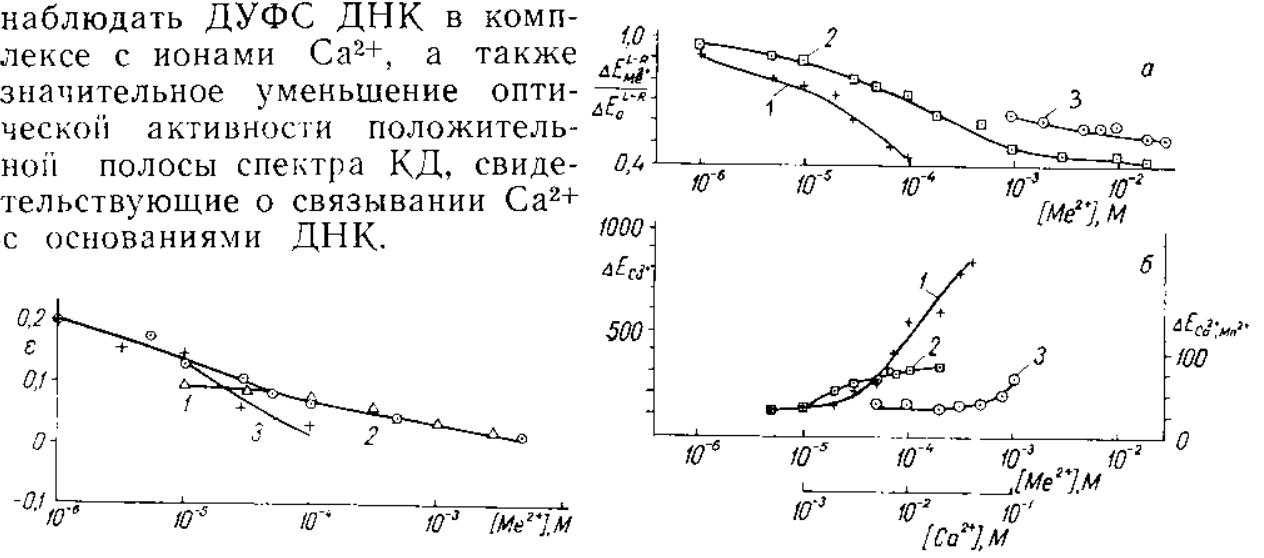

Рıс. 5. Зависимости параметра исключенного объема ДНК от концентрации ионов $\mathrm{Mn}^{2-+}$ и $\mathrm{Cu}^{2+}$ при разном содержанин $\mathrm{Na}^{+}: 1-\mathrm{Mn}^{2+}, 2 \cdot 10^{-2} \mathrm{MNa} \mathrm{Na}^{-} ; 2-\mathrm{Mn}^{2+} ; 3-$ $\mathrm{Cu}^{2+}, 10^{-3} \mathrm{M} \mathrm{Na}+$

Fig. 5 . The DNA cxcluded volume parameter dependences on $\mathrm{Mn}^{2+}$ and $\mathrm{Cu}^{2+}$ ion concertrations with different $\mathrm{NaCl}$ contents. $1-\mathrm{Mn}^{2+}, 2 \cdot 10^{-2} \mathrm{M} \mathrm{Na}^{+} ; 2-\mathrm{Mn}^{2} \mathrm{f}, 3-\mathrm{Cu}^{2+}$, $10^{-3} \mathrm{M} \mathrm{Na}+$

Рис. 6. Зависимости относительного изменения положительной амплитуды спектра КД (a) и положительной амплитуды ДУФС (б) в комплексе с ионами двухвалентных металіов от их концентрацин в растворе при $10^{-3} \mathrm{M} \mathrm{Na} \mathrm{Na}^{+}: 1-\mathrm{Cu}^{2+} ; 2-\mathrm{Mn}^{2+} ; 3-$ $\mathrm{Ca}^{2+}$

Fig. 6. Dependences of the relative clange of the CD spectrun positive amplitude (a) and that of the UFDS (6) of DNA in complex with bivalent metal ions on their concentrations in solution at $10^{-3} \mathrm{M}: \mathrm{Na}+1-\mathrm{Cu}^{2+} ; 2-\mathrm{Mn}^{2+} ; 3-\mathrm{Ca}^{2+}$

Анализ экспериментальных результатов показал [11], что ионы $\mathrm{Mg}^{2+}$ й $\mathrm{Ca}^{2+}$ могут взаимодействовать с гуанином ДНК, образуя хелаты типа $\mathrm{N}(7)-\mathrm{Me}^{2+} \mathrm{O}(6)$, а ионы $\mathrm{Cu}^{2+}$ - и с цитозином, формируя хелаты типа $\mathrm{N}(3)-\mathrm{Cu}^{2+}-\mathrm{O}(2)$. При связывании с ионами $\mathrm{Ca}^{2+}, \mathrm{Mg}^{2+}, \mathrm{Mn}^{2+}$ конформация ДНК изменяется в пределах В-семейства форм. Ионы $\mathrm{Cu}^{2+}$ вызывают особенно сильное изменение конформации ДНК и при $\left[\mathrm{Cu}^{2 \cdot 1-}\right]>4 \cdot 10^{-4} \mathrm{M}$ в буферном и $\left[\mathrm{Cu}^{2+}\right]>10^{-4} \mathrm{M}$ в солевом растворах разрушают двухспиральное состояние биополимера при комнатных температурах. На основании полученных данных можно заключить, что уменьшение [ $\eta]$ ДНК и параметра исключениого объема $\varepsilon$ при взаимодействии с ионами $\mathrm{Mg}^{2+}$ и $\mathrm{Ca}^{2+}\left(\right.$ при $\left.\left[\mathrm{Ca}^{2+}\right]<5 \cdot 10^{-3} \mathrm{M}\right)$ происходит в результате экранирования фосфатных групп макромолекулы при непосредственном связывании двухвалентных нонов. В случае, когда $\left[\mathrm{Ca}^{2+}\right] \geqslant 5 \cdot 10^{-3} \mathrm{M}$, существенное уменьшение характеристической вязкости $[\eta]$, а также параметра \& ДНҚ обусловлено связыванием $\mathrm{Ca}^{2+}$ с азотистыми основаниями, приводящими к более сильному подавлению внутримолекулярных взаимодействий и уменьшению объема макромолекулы.

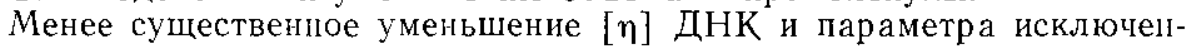
ного объема $\varepsilon$ при взаимодействии со щелочноземельными ионами $\mathrm{Mg}^{2+}$, $\mathrm{Ca}^{2+}$ (по сравнению с действием переходных ионов $\mathrm{Mn}^{2+}, \mathrm{Cu}^{2+}$ ) вызвано их связыванием в основном с фосфатными группами, в то время как ионы $\mathrm{Mn}^{2+}$ и $\mathrm{Cu}^{2+}$ взаимодействуют одновременно и с азотистыми основаниями, что вызывает более сильное уменьшение характеристиче- 
ской вязкости и дальних внутримолекулярных взаимодействий, определяемых величиной параметра $\varepsilon$.

Таким образом, наблюдаемое в эксперименте уменьшенне [n] ДНК при связывании ионов щелочноземельных и переходных металлов (при $I \geqslant 10^{-3} \mathrm{M}$ ) сопровождается подавлением дальнодействня в макромолекуле в результате компенсации отрицательного заряда ДНК при равновесном связывании ионов, а при $\left[\mathrm{Me}^{2+}\right] \geqslant 5 \cdot 10^{-5} \mathrm{M}$ - также и вследствне их экранирующего действия. При рассмотрении эффектов исключенного объема в области $I<2 \cdot 10^{-4} M$ и их вклада в изменение [ $\eta$ ]

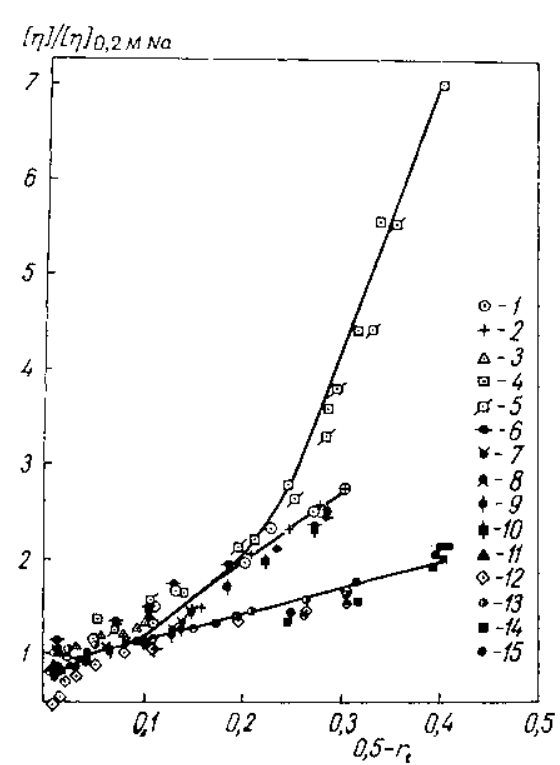
ДНК при связывании $\mathrm{Me}^{2+}$ необходимо учитывать значительное возрастание изгибной жесткости макромолекул, а также влияние двухвалентных ионов на ее величину.

Количественный анализ влияния связывания двухвалентных ионов на величину [П] ДНК и пгараметра $\varepsilon$ можно провести при помощи теории равновесного связыва-

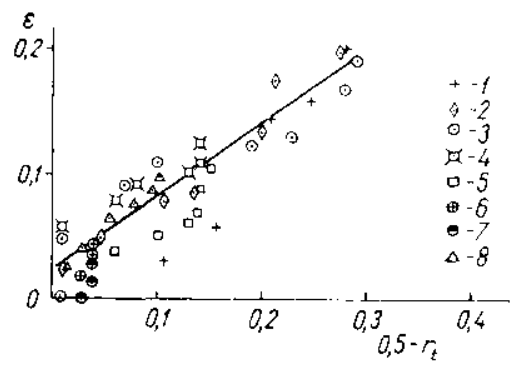

Pнс. 7. Зависимости характеристической вязкости ДНК от величины $\left(0,5-r_{t}\right): 1-\mathrm{Mn}^{2+}$; $2-\mathrm{Cu}^{2+}\left(\left[\mathrm{Na}^{+}\right]=10^{-3} \mathrm{M}\right.$, м. м $\left.19 \cdot 10^{6}\right) ; 3-\mathrm{Mn}^{2+}\left(\left[\mathrm{Na}^{+}\right]=2 \cdot 10^{-2} \mathrm{M}\right.$, м. м. $12 \times$ $\left.\therefore 10^{6}\right) ; 4-\mathrm{Mn}^{2+}\left(\left[\mathrm{Na}^{+}\right]=2 \cdot 10^{-4} \mathrm{M}, \mathrm{M} . \mathrm{M}, 19 \cdot 10^{6}\right) ; 5-\mathrm{Ca}^{2+-}\left(\left[\mathrm{Na}^{-}\right]=2 \cdot 10^{-+} \mathrm{M}\right.$, M. 3. $\left.13 \cdot 10^{6}\right) ; 6-\mathrm{Mg}^{2+}\left(\left[\mathrm{Na}^{+}\right]=10^{-3} \mathrm{M}\right.$, м. м. $\left.13 \cdot 10^{6}\right) ; 7-\mathrm{Mg}^{2+}\left(\left[\mathrm{Na}^{+}\right]=10^{-2} \mathrm{M}, \mathrm{M}\right.$. м. $\left.13 \cdot 10^{6}\right) ; 8-\mathrm{Mg}^{2+}\left(\left[\mathrm{Na}^{+}\right]=10^{-2} \mathrm{M}\right.$, м. м. $\left.13 \cdot 10^{6}\right) ; 9-\mathrm{Ca}^{2-+}:\left(\left[\mathrm{Na}^{+-}\right]=10^{-2} \mathrm{M}\right.$. м. м. $\left.19 \cdot 10^{6}\right) ; 10-\mathrm{Ca}^{2+}\left(\left[\mathrm{Na}^{-+}\right]=10^{-1}\right.$ M. M. M. $\left.19 \cdot 10^{6}\right) ; 11-\mathrm{Ca}^{2} \div\left(\left[\mathrm{Na}^{-1}: \mathrm{C}^{-1} \mathrm{M}\right.\right.$, м. м. $\left.19 \cdot 10^{6}\right) ; 12-\mathrm{Cu}^{2+}\left(\left[\mathrm{Na}^{+}\right]=10^{-3} \mathrm{M}\right.$, м. м. $\left.2,6 \cdot 10^{5}\right) ; 13-\mathrm{Mn}^{2-1^{-}}\left(\mid \mathrm{Na}^{-1}\right]=10^{-3}$ M, м. м. $\left.2,6 \cdot 10^{5}\right) ; 14,15-\mathrm{Mn}^{2+}\left(\left[\mathrm{Na}^{+}\right]=2 \cdot 10^{-4}\right.$ M, м. м. $3,9 \cdot 10^{5}$ и $2,1 \cdot 10^{5}$ cootветственно)

Fig. 7 . Dependences of the DNA intrinsic viscosity on the $\left(0.5-r_{t}\right)$ value: $1-\mathrm{Mn}^{2+}$; $2-\mathrm{Cu}^{2+}\left(\left[\mathrm{Na}{ }^{+}\right]=10^{-3} \mathrm{M} ;\right.$ m. w. $\left.19 \cdot 10^{6}\right) ; 3-\mathrm{Mn}^{2+} \quad\left(\left[\mathrm{Na}^{+}\right]=2 \cdot 10^{-2} \mathrm{M}\right.$, m. w. $12 \times$ $\left.\times 10^{6}\right) ; 4-\mathrm{Mn}^{2-}\left(\left[\mathrm{Na}^{+}\right]=2 \cdot 10^{-4} \mathrm{M}\right.$, m. w. $\left.19 \cdot 10^{6}\right) ; 5-\mathrm{Ca}^{2+}\left(\left[\mathrm{Na}^{\dagger}\right]=2 \cdot 10^{-4} \mathrm{M}, \mathrm{m}\right.$. w. $\left.13 \cdot 10^{6}\right) ; 6-\mathrm{Mg}^{2+}\left(\left[\mathrm{Na}^{+}\right]=10^{-3} \mathrm{M}\right.$, m. w. $\left.13 \cdot 10^{6}\right) ; 7-\mathrm{Mg}^{2+}\left(\left[\mathrm{Na}^{+}\right]=10^{-2} \mathrm{M}\right.$, m. w. $\left.13 \cdot 10^{6}\right) ; 8-\mathrm{Mg}^{2+}\left(\left[\mathrm{Na}^{+}\right]=10^{-2} \mathrm{M}\right.$, m. w. $\left.13 \cdot 10^{6}\right) ; 9-\mathrm{Ca}^{2+}\left(\left[\mathrm{Na}{ }^{+}\right]=10^{-2} \mathrm{M}\right.$, m. w. $\left.19 \cdot 10^{6}\right) ; 10-\mathrm{Ca}^{2+}\left(\left[\mathrm{Na}^{+}\right]=10^{-1} \mathrm{M}, \mathrm{m}\right.$. w. $\left.19 \cdot 10^{6}\right) ; 11-\mathrm{Ca}^{2+}\left(\left[\mathrm{Na}^{+}\right]=10^{-1} \mathrm{M}\right.$, m. w. $\left.19 \cdot 10^{6}\right) ; 12-\mathrm{Cu}^{2+}\left(\left[\mathrm{Na}^{+}\right]=10^{-3} \mathrm{M}, \mathrm{m}\right.$. w. $\left.2 \cdot 6 \cdot 10^{5}\right) ; 13-\mathrm{Mn}^{2+}\left(\left[\mathrm{Na}^{+}\right]=10^{-3}\right.$ M. m. w. $\left.2 \cdot 6 \cdot 10^{5}\right) ; 14,15-\mathrm{Mn}^{2+}\left(\left[\mathrm{Na}^{+}\right]=2 \cdot 10^{-4} \mathrm{M}, \mathrm{m}\right.$. w. $3 \cdot 9 \cdot 10^{5}$ and $2 \cdot 1 \cdot 10^{5}$, res. pectively)

Рис. 8. Занисимость параметров исключенного объема ДНК от величнны $\left(0,5-r_{t}\right)$ : $1-\mathrm{Cu}^{2+} ; 2-\mathrm{Mn}^{2+} ; 3-\mathrm{Ca}^{2+}, 10^{-3} \mathrm{M} \mathrm{Na}+4-\mathrm{Mg}^{2+} ; 5-\mathrm{Ca}^{2+}, 10^{-3} \mathrm{M} \mathrm{Na} ; 6-$ $\mathrm{Mg}^{2+} ; 7-\mathrm{Ca}^{2+}, 10^{-1} \mathrm{M} \mathrm{Na}+; 8-\mathrm{Mn}^{2+}, 2 \cdot 10^{-2} \mathrm{M} \mathrm{Na}+$

Fig. 8. Dependences of the DNA excluded volume parameter on the $\left(0.5-r_{t}\right)$ value: $1-$ $\mathrm{Cu}^{2+} ; 2-\mathrm{Mn}^{2+} ; 3-\mathrm{Ca}^{2+}, 10^{-3} \mathrm{M} \mathrm{Na}+4-\mathrm{Mg}^{2+} ; 5-\mathrm{Ca}^{2+}, 10^{-3} \mathrm{M} \mathrm{Na} ; 6-\mathrm{Mg}^{2+}$; $7-\mathrm{Ca}^{2}+, 10^{-1} \mathrm{M} \mathrm{Na}+8-\mathrm{Mn}^{2+}, 2 \cdot 10^{-2} \mathrm{M} \mathrm{Na}{ }^{+}$

ния ионов и экспериментальных данных о константах связывания. Нзу-

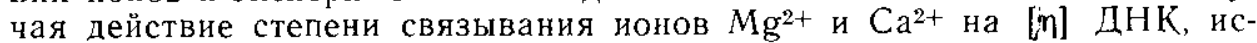
пользовали систему уравнений Скетчарда для случая конкуренции ионов и учета антикооперативности связывания, примененную нами ранее для ионов $\mathrm{Mn}^{2+}$ и $\mathrm{Cu}^{2+}$ [4]. При вычислении степени связывания $r_{t}$ значение константы связывания для ионов $\mathrm{Mg}^{2+}$ и $\mathrm{Ca}^{2+}$ было заим- 
ствовано из работы [13], а значение параметра w, характеризующего электростатическую энергию отталкивания связанных с ДНК $\mathrm{Me}^{2+}$, из [6]. Полученные зависимости [ $\eta]$ ДНК и параметра исключенного объема $\varepsilon$ от степени связывания ионов щелочноземельных металлов $\mathrm{Mg}^{2+}$ и $\mathrm{Ca}^{2+}$ представлены на рис. 7 и 8 , где они сравниваются с аналогичными зависимостями для ионов переходных металлов $\mathrm{Mn}^{2+}$ и $\mathrm{Cu}^{2+}$. Величина $\left(n-r_{t}\right)$ (где $n$ - число возможных мест связывания, приходящихся на нуклеотид и для ДНК равное $0,5[3,6,12,13])$ пропорциональна эффективному среднему заряду сегмент. При значениях $\left(0,5-r_{t}\right)<0,2$ зависимость характеристиче-

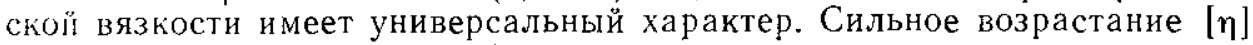
ДІІК при $2 \cdot 10^{-4} \mathrm{M} \mathrm{Na}$ обусловлено существенным увеличением статистического сегмента ДНК в этой области $I[7,8]$ вследствие усиления ближних внутримолекулярных электростатических взаимодействий заряженных груш макромолекул при малых степенях экранирования. В возрасгание величины [ $\eta]$ при $r_{t}<0,2$ также вносит вклад и дальнодействие, характеризуемое параметром є. Зависимость параметра исключенного объема ДНК от величины $\left(0,5-r_{t}\right)$ является универсальной .Һ.я различных ионов и имеет линейный характер. Характер этой зависимости обуслов.ІеІ пропорциональностью $\varepsilon$ параметру $z$, линейно зависящему от заряда мономерной единицы макромолекулы и характеризующему средий эффективный потенциал взаимодействия сегментов [14].

Вычисление степени связывания двухвалентных ионов в соответствии с теорией Мэннинга [15] привело в условиях $\left[\mathrm{Na}^{+}\right]=2 \cdot 10^{-4} \mathrm{M}$ к изменению величины $r^{m}$ от 0,40 при $\left[\mathrm{Me}^{2+}\right]=5 \cdot 10^{-6} \mathrm{M}$ до 0,44 при $\mathrm{Me}^{2+}=5 \cdot 10^{-3} \mathrm{M}$. Столь малое изменение степени связывания не может объяснить значительного уменьшения характеристической вязкости ДНК, наблюдаемого в эксперименте. Как показано в работе [16], эта теория имеет ограниченную область применимости н дает точные результаты при низких ионных силах только при рассмотрении ситуации вдали от полинона.

Универсальные зависимости характеристической вязкости ДНК и параметра исключенного объема от степени связывания различных ионов металлов свидетельствуют в пользу того, что связанные с макромолекулой ионы, а не входящие в диффузное облако, определяют структуру раствора вблизи биополимера и его конформационное состояние.

За многочисленные и плодотворные обсуждения и стимулирующий интерес к данной работе авторы выражают благодарность Э. В. Фрисман, М. Д. Франк-Қаменецкому и В. И. Иванову.

\section{EFFECT OF ALKALI-EARTH AND TRANSITION METAL IONS ON HYDRODYNAMIC A.ND MACROMOLECULAR PARAMETERS OF DNA}

S. V. Kornilova, A. G. Shkorbatov, Yu. P. Blagoi

Institute for Low Temperature Physics and Engineering,

Academy of Sciences of the Ukrainian SISR, Kharkov

Sum m a r y

DNA intrinsic viscosity $[\eta]$ and the excluded volume parameter $\varepsilon$ are stated to depend on the concentrations and the binding degrees of $\mathrm{Mg}^{2+}, \mathrm{Mn}^{2+}, \mathrm{Ca}^{2+}, \mathrm{Cu}^{2+}$ ions with different $\mathrm{NaCl}$ contents $\left(2 \cdot 10^{-4}+10^{-1} \mathrm{M}\right)$. The substantial changes of the [ग] value and the parameter $\varepsilon$ in the presence of small contents of bivaient metal ions are show to be due to the ion binding to the phosphate grouss and nitrogen bases of DNA. Bivalent ion $\left(\mathrm{Me}^{2+}\right)$-DNA binding results in the suppression of long-range effects in a macromolecule with concentrations by some orders of magnitude lower than those in the case of monovalent ions. The effect of transition metal ions $\left(\mathrm{Mnn}^{2+}, \mathrm{Cu}^{2+}\right)$ on the value and the excluded volume parameter is greater than that of the alkali-earth $\left(\mathrm{Ca}^{2+}, \mathrm{Mg}^{2+}\right)$ ones due to their binding not only to DNA phosphate groups but also to the nitrogen bases even with small concentrations $\left(5 \cdot 10^{-6} \mathrm{M}\right)$. The intrinsic viscosity and the excluded volume parameter are shown to depend universally on the binding degree of bivalent ions. 


\section{СПИСОК ЛИТЕРАТУРЫ}

1. Благой Ю. П., Корнилова С. В., Сохан В. Н. Изучение изменения характернстической вязкости ДНК при взаимодействии с ионами $\mathrm{Cu}^{2+}$ и $\mathrm{Mn}^{2+} / /$ Moseкуия. бнология - 1982,-16, № 1.- C. $210-216$

2. Bivalent metal ion effects on chain stiffness and excluded volume of DNA/ Yu. P. Bilagoi, S. V. Kornilova, A. G. Shkorbatov, S. A. Egupov// Stud. biophys.1985.-108, N 1.- P. .17-24.

3. Reuben J, Gabbay E. Binding of manganese (II) to DNA and the competitive effects of melal ions and organic cations. An electron paramagnetic resonance study // Biochemistry.-1975.-14, N 6.—P. $1230-1235$.

4. Korniloua S. V., Blagoi Yu. P., Shkorbatou A. G. Melal ion effect on molecular sites and intermolecular interaction in DNA// Water and ions in biol. syst.- New York: Plenum press, $1985 .-856 \mathrm{p}$.

5. Нсследованше влияния ионов $\mathrm{Mn}^{2+}$ и $\mathrm{Mg}^{2+}$ на конформацию молекулы ДНК/ Н. А. Косьяненко, Г. Сэльман-Хусейн Соса, В. Н. Уверский, Э. В. Фрисман $/ /$ Молекуляр. биология-- 1987.-21, № 1.- C. $140-144$.

6. Clement R. M., Strum J., Daune M. P. Interaction of metallic cations with DNA. 6. Specific binding of $\mathrm{Mg}^{2+}$ and $\mathrm{Mn}^{2+} / /$ Biopolymers.- 1973.-12, N 2. - P. 405-421.

7. Фрисман 3. B. Оптическое и гидродинамическое поведение ДНК и ее комплексов с биологитески активными молекулами // IV Междунар. биофиз. конгр.: Тез. докл.Пущино, 1973.- T. 1.- С. 301.

8. Hagerman $P$. I. Investigation of the flexibility of DNA using transient electric birefrigence // Biopolymers. - 1983-20, N 4.- P. 1503-1535

9. Франк-Каменецкий $M$. Д. Флуктуационная подвижность ДНК // Молекуляр. биология.-1983,-17, ㅊo 3.- C. 539-652.

10. Ross $P$. D., Scruggs $R$. L. Viscosity study of DNA. II. The effect of simple salt concentration of the riscosity of high-molecular weight DNA ard application of viscometry to the study of DNA isolated from $\mathrm{TH}$ and $\mathrm{TS}$ bacteriophage mutants // Biopolymers. - 1968 -6, N 4.- P. $1005-1018$.

11. Влияние ионов металлов на структуру ДНК разного молекулярного веса/ Ю. П. Блалой, С. В. Корнилова, В. А. Сорокин, А. Г. Шкорбатов // Stud. biophys.1986.-114, N $1 / 3-$ C. $263-268$

12. Благой 10 . П., Сорокин B. A., Валеев B. А. Спектральное исследование связывания оснований ДНК с ионами магния и кальция// Молекуляр. бнология.- 1980,-14, № 3.- - C. $5915-605$.

13. Zimmer $C h$. Binding von Divalent Metallionen un Nuclcinsaüren und Wirkungen auf die Konformation der Deoxyribonucleinsaüre//Zeitshrift Chem,- 1971._11, N 12, P. $441-458$.

14. Jифиаи Н. М., Гросберг А. Ю., Хохлов А. Р. Объемные взаимодействия в статистической физике полимерных макромолекул//Успехи физ. наук.- 1979.-127, № 3.- C. $353-388$.

15. Manning $G, S$. The molecular theory of polyelectrolyte solutions with applications to the eiectrostatic properties of polynucleotides//Quart. Rev. Biophys - 1978.-11, N 2 - P. $179-246$.

16. Лукайн А. В., Аниелевич B. В., Франк-Қаменецкий М. Д. Современное состояние теории сильно заряженных полиэ.тектролитов типа ДНК.-Пушино, 1985. 29 c.

17. Расчет характеристической вязкости синтетических и биологических полиэлектролитов различной жесткости / С. В. Слоницкий, Э. В. Фрисман, А. Қ. Валеев и др.// Молекуляр. биология-1980--14, № 3-C. $484-495$.

18. Reinert K. E., Geller K. Interactions of different substances with polyelectrolyte DNA // Stud. biophys. - 1968.-30, N 10.- C. $65-73$.

Физ,-техн. ик-т низких температур

Получено 11.05 .89

АН УССР, Харьков

удК $577.963 .32 ; 539.199$

\section{С. Н. Волков, А. М. Косевич, Г. Е. Вайнреб \\ ТЕОРЕТИЧЕСКОЕ ИЗУЧЕНИЕ \\ НИЗКОЧАСТОТНЫХ КОЛЕБАНИЙ МАКРОМОЛЕКУЛ ДНК}

Нсследованы колебания структурных злементов полинуклеотидной џепи относительно равновесной конформации двутяневьх ДНК. В рассмотрение включены относительные движения нуклеотидов, связанных попарно водородными связями, изгибания поли нуклеотидных чепей и внутринуклеозидная подвиюность. Выполнен анализ нормальных колебаний двутяжевой цепи и определена структура низкочастотного спектра колебаний ДНК. Нспользуя теоретические результаты и их согласие с данньми спектроскопии комбинационного рассеямия (КР), предложена интерпретация наблюдаемьх особенностей в спектрах низкочастотных колебаний ДНК. 